\title{
Genotoxicological Effects of Heavy Metals on Humans Cells
}

\author{
Velickova Nevenka*, Kamcev Nikola \\ Faculty of medical science, University” Goce Delcev” - Stip, Republic of Macedonia \\ *Corresponding author: nevenka.velickova@ugd.edu.mk
}

Received July 31, 2014; Revised August 14, 2014; Accepted September 03, 2014

\begin{abstract}
Aims of this study was to detect cytogenetic damage in mine workers working in a lead-zinc mine, which could be associated with a combined exposure to lead, zinc and cadmium. Methods: This study involved 120 mine workers from the lead-zinc mine in Macedonia, and a control group (30) of local people who had never worked in the mine. The authors used peripheral blood lymphocytes as the target material. The total share of structural chromosome aberration (SCA) were searched out over the 3 years of monitoring. Also they measured the blood level of lead, zinc and cadmium with ISP-AES. Results: The authors concluded increased blood lead level in the exposed group (Mean= O,089mg/l) and in 20\% in the control group (Mean=0,066mg/l); increased zinc blood level in the exposed (Mean=1,391mg/l) and in control group (Mean=1,074mg/l); increased cadmium blood level in $62 \%$ of the exposed (Mean=0,007mg/l) and in 50\% of the control group (Mean=0,006mg/l); Chromosomal aberrations (like dicentric and acentric chromosome) were found to be elevated in $7 \%$ of exposed individuals (mine workers) non in the control group. Both chromosome type aberrations in the exposed group were accompanied with anemia, leucocitosis and anisocitosis. Conclusion: The group of exposed people showing increased levels of chromosome abnormalities has a higher risk of developing cancer and other deseasses.
\end{abstract}

Keywords: genotoxic agents, heavy metals, professionally exposed

Cite This Article: Velickova Nevenka, and Kamcev Nikola, "Genotoxicological Effects of Heavy Metals on Humans Cells.” American Journal of Environmental Protection, vol. 2, no. 4 (2014): 71-73. doi: 10.12691/env-2-4-2.

\section{Introduction}

The analysis and quantification of genomic changes are important steps in monitoring and in the elucidation of mechanisms leading to critical health effects. The main conceptual basis for using cytogenetic assays for biological monitoring is that genetic damage in easily available cells, such as peripheral blood lymphocytes, reflects comparable events in target cells. Too little is known about the chromosomal effects of metal exposure. The aim of this study was to detect cytogenetic damage in mine workers working in a lead-zinc mine, which could be associated with a combined exposure to lead, zinc and cadmium like heavy metals and to determine risk factors for the frequencies of structural chromosomal aberrations in peripheral blood lymphocytes of the mine workers. Chromosomal aberrations in human peripheral lymphocytes are well established biomarkers of exposure to occupational or environmental genotoxic agents. Underground miners are particularly exposed to complex mixtures of chemicals (e.g., heavy metals, diesel emission particles and dust), many of which are known mutagens (Johnson, 1998; Keshava and Ong, 1999; Rojas et all., 1999; Scheepers et all., 2002; Wolf et all., 2004; Donbak et all., 2005). Biochemical monitoring for chemical agents, involves the measurement of the amount of a carcinogen or its metabolites present in cells, tissues, or body fluids.
Analysis of internal dose takes into account individual differences in absorption or bioaccumulation of the compound in question. The present article attempts to synopsize current knowledge of the chromosomal effects caused by heavy metal exposure, points out the existing gaps in this knowledge and discusses future research needs.

\section{Material and Methods}

Our study involved 120 mine workers from the leadzinc mine in Macedonia, and the control group (30) of local people who had never worked in the mine. The health and occupational histories of the subjects and controls in respect of age, sex, duration of exposure to pollutants, smoking and drinking habits and drug intake, if any, were recorded on a standard proforma. The data were taken over a period of 3 year. According to the questionnaires all the participants were healthy and had not been regularly using prescription medicines nor been exposed to radiation and/or chemicals outside their work environment during the month prior to sampling. We used peripheral blood lymphocytes as the target material. The total share of structural chromosome aberration were searched out over the 3 years of monitoring. Also we measured the blood level of lead, zinc and cadmium with ISP-AES. It is a common and simple laboratory technique capable of routine analysis of biological samples and has been used 
to determine very low levels of heavy metals in human serum. The use of stable isotopes or tracers to study heavy metals absorption in humans with subsequent analysis by mass spectrometry has been reported in the literature. The overall aim of this study was to investigate if heavy metals like variety of environmental agents can cause cytogenetic damage and other systematic effects in mine workers. Blood samples were collected by venipuncture in sterile heparinized and coded tubes. Lymphocytes were cultured for $72 \mathrm{~h}$ at $37^{\circ} \mathrm{C}$ (Moorhead et al., 1960). Whole blood cultures were prepared within 24h of collection using Parker culture medium (BioWhittaker) enriched with 4\% (v/v) fetal bovine serum (Sigma), 2\% (w/v) L-glutamine (Gibco BRL) and 2\% (w/v) phytohemaglutinin-M (Gibco $\mathrm{BRL}$ ), $16 \mu \mathrm{g} \mathrm{mL}$ colchicine (Sigma) being added 45 to 50 min before harvesting. The cells were collected by centrifugation, resuspended briefly in pre-warmed hypotonic $0.075 \mathrm{M} \mathrm{KCl}$ and fixed twice in acetic acid/methanol (1:3, v/v). The preparations were air dried at room temperature and stained with $2.5 \%(w / v)$ Giemsa in methanol. As many as 100 good metaphases were screened for individual chromosomal aberrations. Fluorescence in situ hybridization was a reliable method for monitoring chronic occupational clastogen exposure. Fluorescence in situ hybridization (FISH) is a powerful new technique that allows numerical or structural chromosome aberrations to be detected in interphase cells.

\section{Results And Discusion}

Results show increased blood lead level in the exposed group (Mean=0,089 mg/l) and in 20\% in the control group (Mean=0,066); increased zinc blood level in the exposed (Mean=1,391) and in the control group (Mean=1,074); increased cadmium blood level in $62 \%$ of the exposed (Mean=0,007) and in 50\% of the control group (Mean=0,006);

Both chromosome type aberrations viz. dicentrics, rings, acentric fragments, chromosomal gaps and chromosome breaks and chromatid type aberrations viz. chromatid gaps, chromatid breaks and isochromatid exchanges were encountered in the exposed group. The most frequent aberrations encountered in the miner populations were dicentric and acentric fragments. Chromosomal aberrations (like dicentric and acentric chromosome) were found to be elevated in $7 \%$ of exposed individuals (mine workers) non in the control group. Achromatic lesions (gaps) were not elevated as true chromosomal aberrations.

In the present study, we used an interphase FISH procedure to perform cytogenetic analyses on the blood cells (lymphocytes).

The biochemical analyses show:

- $48 \%$ of the miners (exposed group) have exposure period above 20 years, 29\% between 10-20years and the rest 23\% have exposure period under 10 years;

- If we know that normal BLL (blood lead level) is $0,04-0,07 \mathrm{mg} / \mathrm{l}$ we conclude that all male subject in the exposed group have above normal BLL. In the control group $20 \%$ of the male subject have above normal BLL;

- If we know that normal BZL (blood zink level) is 0,1 $\mathrm{mg} / \mathrm{l}$ we conclude that all male subject in the exposed and in the control group have above normal BZL;
- If we know that normal BCL is $0,005 \mathrm{mg} / \mathrm{l}$ we conclude that $62 \%$ of male subject in the exposed group have above normal BCL. In the control group $50 \%$ of the male subject have above normal BCL;

- that blood lead, zink and cadmium level grow up during job exposure;

- highly significant negative correlation between the numbers of red blood cells and hemoglobin and blood heavy metals levels;

- positive correlation between the numbers of leukocytes and blood lead levels;

- the epidemiological survey showed that nearly all workers complained of headache;

- whereas 25 workers out of 70 with long exposure were found to be suffering from various respiratory tract diseases like asthma, irritation and watering of eyes were other symptoms common to all;

- overt signs of acute intoxication include dullness, restlessness, irritability, poor attention, span, headaches, muscle tremor, abdominal cramps, kidney damage, hallucinations, and loss of memory, encephalopathy occurring at blood lead levels of 0,1 $\mathrm{mg} / \mathrm{l}$

- significant association has been established, without evidence of a threshold, between blood lead level and high diastolic blood pressure in people aged 21-55;

Cytogenetic monitoring is becoming an integral part of preventive medical surveillance in occupations with actual or potential genetic hazard. Although personal protective equipment such as overalls and safety boots, helmets and masks are normally used the mine workers are often old and/or in bad condition. We find stable genome who not including chromosomal aberrations during job exposure. But, the chromosomal damage observed in the mining populations studied may be attributable to the complex mixture of genotoxic agents to which the miners may have been exposed. Cytogenetic studies in humans exposed to lead (blood lead levels $>40 \mu \mathrm{g} / \mathrm{dl}$ ) have given conflicting results. Several explanations for the discrepancy have been suggested. The duration of cultures derived from lead-exposed people might be responsible for some of the variability between different reports. When lymphocytes are cultured for 72 hrs a large proportion of the cells are already in their second or third metaphase. Thus there is a possibility that some of the aberrations are not derived from in vivo exposure but develop duringthe culture period due to existing lead. However, many authors reported that lead at a concentration of about 3300 times the concentration in the blood of occupationally leadexposed workers did not produce chromosomal aberrations in vitro in human lymphocytes. There is, however, also a possibility that the lymphocytes with chromosomal damage tend to have a delay in their blast transformation, so that more first division metaphases are actually scored at $72 \mathrm{hr}$ in lead-exposed subjects than normally. The results of in vivo and in vitro studies with the same test system, human lymphocytes, sometimes disagree. Diverse factors can cause variation in the background level of chromosomal aberrations, including cell-culture conditions (medium, incubation time) and population variables such as dietary habits, location and environmental factors such as airpollution. At least three factors could be related to the low frequency of chromosomal aberrations found in 
this study. The results of in vivo and in vitro studies with the same test system, human lymphocytes, sometimes disagree. This inconsistency may be due to differences in concentrations at target sites on one hand, or to the capacity of the body to eliminate heavy metals (lead, zinc and cadmium).

The significance of these results has been questioned. Lead interferes with the activity of several of the major enzymes involved in the biosynthesis of haem. The only clinically well-defined symptom associated with the inhibition of haem biosynthesis is anaemia. Leukocytosis persisting for approximately 12 hours after fever dissipates is one of the hallmarks of metal fume fever. However, in the real world people are exposed to mixtures, not single chemicals. Although various substances may have totally independent actions, in many cases two substances may act at the same site in ways that can be either additive or nonadditive. Many even more complex interactions may occur if two chemicals act at different but related targets. In the extreme case there may be synergistic effects, in which case the effects of two substances together are greater than the sum of either effect alone. In reality, most people are exposed to many chemicals, not just one or two, and therefore the effects of a chemical mixture are extremely complex and may differ for each mixture depending on the chemical composition. This complexity is a major reason why mixtures have not been well studied. In this review we attempt to illustrate some of the principles and approaches that can be used to study effects of mixtures.

\section{Conclusions}

The authors concluded increased blood lead level in the exposed group (Mean= 0,089) and in $20 \%$ in the control group (Mean=0,066); increased zinc blood level in the exposed (Mean=1,391) and in control group (Mean=1,074); increased cadmium blood level in $62 \%$ of the exposed (Mean=0,007) and in 50\% of the control group (Mean=0,006); Chromosomal aberrations (like dicentric and acentric chromosome) were found to be elevated in $7 \%$ of exposed individuals (mine workers) non in the control group. The mine workers with chromosomal aberrations work over 20 years in the mine, and they have positive correlation between blood levels of heavy metals (lead, cadmium and zinc) and chromosomal aberrations. Both chromosome type aberrations in the exposed group were accompanied with anemia, leucocitosis and anisocitosis. The earliest concern of the research work in the field of occupational diseases was intoxication with heavy metals. $85 \%$ of the workers with long exposure were found to be suffering from various respiratory tract diseases like asthma and respiratory infections. Our research showed that nearly all workers complained of headache.

\section{References}

[1] ATSDR (Agency for Toxic Substances and Disease Registry) (1999): Toxicological profile for lead. U.S. Department of Health and Human Services, Public Health Service. Atlanta, Georgia.

[2] Donbak L, Rencuzogullari E, Yavuz A and Topaktas M (2005): The genotoxic risk of underground coal miners from Turkey. Mutat Res 588:82-87.

[3] FenechM (2002): Biomarkers of genetic damage for cancer epidemiology. Toxicology 181:411-416.

[4] Gartside, PS. (1986): The relationship between blood lead levels and blood pressure and its cardiovascular risk implications. American journal of epidemiology, 124:864-867 (letter).

[5] International Agency for Research on Cancer. (IARC): Overall evaluations of carcinogenicity: an updating of IARC monographs volumes 1-42. Lyon, 1987:230-232 (IARC Monographs on the Evaluation of Carcinogenic Risks to Humans, Suppl. 7).

[6] International Agency for Research on Cancer. Some metals and metallic compounds. Lyon, 1980:325 (IARC Monographs on the Evaluation of Carcinogenic Risks to Humans, Vol. 23).

[7] Lin, J., Lin-Tan, D., Hsu, K. and Yu, C. (2003): Environmental lead exposure and progression of chronice renal diseases in patients without diabetes. The new england journal of medicine. 348: 277-286.

[8] Moore, MR. (1988): Haematological effects of lead. Science of the total environment, 71:419-431.

[9] Padmaja, T., Ramana Devi, Ch. V. And Reddy P. P (2002): Analysis of Chromosomal Aberrations in Mint Factory Workers, Int J Hum Genet, 2 (2): 81-86.

[10] Savage JRK (2004) On the nature of visible chromosomal gaps and breaks. Cytogenet Genome Res 104:46-55.

[11] Scheepers PT, Coggon D, Knudsen LE, Anzion R, Autrup H, Bogovski S, Bos RP, Dahmann D, Farmer P, Martin EA, et al. (2002) Biomarkers for occupational diesel exhaust exposure monitoring (biomodem) - A study in underground mining. Toxicol Lett 134:305-317.

[12] Smerhovsky Z, Landa K, Rössner P, Juzova D, Brabec M, Zudova Z, Hola N, Zarska H and Nevsimalova E (2002) Increased risk of cancer in radon-exposed miners with elevated frequency of chromosomal aberrations. Mutat Res 514:165-176.

[13] Sergio R. Santa Maria, Margarita Arana and Oswaldo Ramirez (2007): Chromosomal aberrations in peripheral lymphocytes from male native miners working in the Peruvian Andes, Genetics and Molecular Biology, 30, 4, 1135-1138.

[14] Sorsa, M., Maki-Paakkanen, J., Vainio, H. (1982b): Identification of mutagen exposures in the rubber industry by the sister chromatid exchanges method. Cytogenet Cell Genet, 33: 68-73.

[15] Sorsa, M., Maki- Paakkanen, J., Vainio, H. (1983): A chromosome study among workers groups in the rubber industry. Scand Journal of Work Environmental Health, 9: 43-47.

[16] Sorsa, M., Yager, JW (1987): In: Cytogenetics Basic and Applied G Obe and A Basler (Eds.). Bedin: Springer Verlag.

[17] Sasiadek, M. (1992): Cytogenetic studies of workers from the rubber industry. Mutation Research, 279: 195-98.

[18] Sasiadek, M., Jarventaus, H., Sorsa, M. (1991a): Sister chromatid exchanges induced by 1, 3-butadiene and its epoxide in CHO Cells. Mutation Research, 263:47-50.

[19] Sasiadek, M., Norppa, H., Sorsa, M. (1991): 1, 3-butadiene and its expoxides induced sister chromatid exchanges in human lymphocytes in vitro. Mutation Research, 261: 117-21.

[20] US Environmental Protection Agency. Air quality criteria for lead. Research Triangle Park, NC, 1986 (Report EPA-600/8-83/028F).

[21] Wolf G, Arndt D, Kotschy-Lang N and Obe G (2004): Chromosomal aberrations in uranium and coal miners. Int J Radiat Biol 80:147-153. 